\title{
PENGAJARAN PENEBUSAN DOSA TERHADAP KEYAKINAN KESELAMATAN DI KALANGAN PEMUDA GKST JEMAAT IMANUEL LAMBARESE
}

\author{
Greis, Buce Zeth Tuhumury
}

\begin{abstract}
Abstrak
Dosa merambat ke seluruh dunia oleh sebab kejatuhan manusia pertama yaitu Adam dan Hawa yang telah melanggar perintah dan ketetapan Tuhan (ketidaktaatan) di taman Eden (Kej. 3:1-24), keinginan daging, dan godaan iblis. Kejatuhan manusia berakibat fatal yaitu maut (Kej. 2:17). Karena kasih-Nya yang begitu besar (Yoh. 3:16) atas kehendak-Nya. Yesus Kristus lahir, mati di kayu salib, serta bangkit dari kematian untuk mengalahkan maut sebagai bukti bahwa Allah telah menebus manusia dari lumpur dosa. Dengan karya penebusan dosa Allah memberikan pengampunan, pembenaran, pengudusan melalui Yesus Kristus di kayu salib sehingga manusia beroleh jalan keselamatan bagi yang percaya kepada-Nya. Bertitik tolak dari pengajaran penebusan dosa ini. Yang menarik bagi penulis untuk melakukan penelitian ini, karena melihat keadaan pemuda di GKST Jemaat Imanuel yang telah mengikuti katekisasi (pembinaan iman) di dalamnya ada pengajaran penebusan dosa. Namun, banyak kawula muda yang telah menjadi anggota gereja yang memiliki masalah dengan keyakinan hingga pada akhirnya meninggalkan Kristus. Penulis menggunakan metode kualitatif atau Library Research di mana Alkitab sebagai sumber primer dan menggunakan buku-buku tambahan, melakukan wawancara. Serta, observasi langsung di kalangan pemuda di GKST Jemaat Imanuel Lambarese untuk mengetahui bagaimana pengajaran penebusan dosa terhadap keyakinan keselamatan. Maka hasil penelitian menunjukkan pemuda kurang mengerti dengan pengajaran karena di dalam materi masih banyak yang kurang seperti perbuatan penebusan di dalam Perjanjian Lama kurang disinggung. Pemuda menjawab pertanyaan, pengajaran penebusan dosa ada di dalam khotbah, kurang yang menjawab pengajaran ada di dalam pembinaan iman. Pemuda memiliki keyakinan keselamatan. Namun tidak dapat memberikan bukti-bukti dalam memperoleh keselamatan dan unsur-unsur karya keselamatan yang menjadi menjadi dasar yang teguh seorang pribadi memiliki keyakinan keselamatan.
\end{abstract}

Kata-kata Kunci: Penebusan dosa, Keselamatan, Pertobatan, Kristus, Pemuda, GKST.

\section{Pendahuluan}

\section{Latar Belakang Masalah}

Manusia dan dosa merupakan bagian yang tidak terpisahkan, bahkan sejak manusia masih dalam kadungan ia berdosa. Hal ini yang sangat sulit lepas dari manusia. Kerap kali orang-orang mengatakan istilah, bahwa "kita manusia biasa yang tidak luput dari dosa" namun manusia juga sadar bahwa dosa pada akhirnya berujung pada maut. Orang-orang yang menganut 
agama atau punya kepercayaan mengakui bahwa adanya Tuhan yang Esa, pencipta langit dan bumi, sehingga berusaha meminta pengampunan kepada Allah yang Esa itu agar lepas dari jerat dosa dan bebas dari hukuman. Para pelaku dosa adalah orang-orang yang tercela, baik dalam pandangan Tuhan maupun manusia. Akan mendapat ganjaran berupa hukuman dan siksaan dari Tuhan. Sebagai manusia berakal dan beriman menginginkan hidup yang bahagia dan bebas dari celaka dan sengsara di dunia maupun di akhirat. ${ }^{1}$

Berbicara masalah dosa tidak semua orang tahu bahwa ada pekerjaan penebusan (beberapa orang bergumul dengan teologi) ${ }^{2}$, di mana dosa yang begitu keji dan kotor itu dapat ditebus dengan darah yang kudus, oleh darah yang tak bercela dan suci. Siapakah yang dapat memberikan darah penebusan tersebut? $M$ hanya satu pribadi, pribadi yang sudah disediakan sejak dahulu kala, sejak manusia pertama jatuh ke dalam dosa. Pribadi yang sudah dijanjikan dari masa nenek moyang, Abraham, Ishak, dan Yakub.

Di dalam kekristenan ada janji penebusan dosa atau dengan kata lain penyucian hubungan dengan Allah, manusia berusaha mencari kebenaran di hadapan Allah dengan memberikan korban penebusan kepada Allah, yang dilakukan oleh para imam yang dimandatkan sebagai pengantara antara Allah dengan manusia, meskipun demikian korban tersebut tidak akan pernah cukup bahkan ketika hal itu dilakukan berulang kali.

Seperti halnya korban-korban persembahan menurut hukum Taurat tidak dengan sendirinya menghapus dosa, demikian pula tidak mungkin korban-korban itu akan menghapus dosa. $^{3}$ Korban persembahan yang diberikan tidak cukup untuk memperbaiki hubungan Allah dengan manusia, dengan darah korban- korban yang diberikan sebagai tanda dan simbol penyucian agar manusia layak di hadapan Tuhan. Darah Korban persembahan tidaklah cukup untuk menghapuskan dosa, bahkan secara sempurna untuk membenarkan manusia di hadapan Allah. Karena korban yang diberikan bukan atas kehendaknya sendiri. Berdasarkan apa yang telah dilakukan Allah dalam mempersiapkan raga bagi Kristus (yaitu kodrat manusia) supaya Ia memenuhi syarat untuk menjadi penebus dan pembela. Dengan bersatunya dua kodrat dalam diri-Nya, Ia menjadi pengantara yang pantas untuk menengahi Allah dan manusia. Ia bisa menjadi manusia sehari-hari yang merentangkan tangan-Nya pada Allah dan manusia, sang pembawa damai untuk mendamaikan mereka, dan ikatan kekal antara Allah dan makhluk ciptaan. $^{4}$

Kalau melihat keadaan ini, masa sekarang pun masih banyak orang yang berusaha mencari jalan keselamatan, apakah itu dilakukan dengan melihat secara duniawi bahwa siapa yang paling kuat, makhluk apa yang paling indah untuk disembah, hal-hal yang paling nampak luar biasa dianggap sebagai penguasa tanpa diketahui bahwa manusialah makhluk yang paling indah dan sempurna diciptakan Tuhan dari segala ciptaan, maka segala yang ada di dunia ini hanyalah sebatas ciptaan, menjadi pertanyaan di mana manusia harus mencari jalan keselamatan?

Pada masa Perjanjian Baru di mana disana telah digenapi apa yang telah Allah janjikan untuk hadir-Nya sang penyelamat yaitu Imamat yang Rajani, Anak Domba Allah yang akan menjadi korban persembahan sempurna, dengan darah-Nya Ia membersihkan kejahatan manusia. Bukan hanya sekadar membersihkan tubuh kita atau tindakan kita, melainkan membersihkan hati

\footnotetext{
${ }^{1}$ Tarpin, "Pandangan Kristen Tentang Dosa: Asal Muasal dan Cara Menebusnya," Jurnal Ushuluddin 16, No. 2 (Juli 2010): 221, diakses 22 Februari 2019, http://ejournal.uin-

suska.ac.id/index.php/ushuludin/article/view/677.

${ }^{2}$ Sudhiarsa, 105.

${ }^{3}$ Matthew Henry, Tafsiran Matthew Henry: Surat Ibrani, Yakobus, 1 \& 2 Ptr. 1 - 3 Yohanes, Yudas, Kitab Wahyu (Surabaya: Momentum, 2016), 161.

${ }^{4}$ Henry, 163.
} 
nurani, sumber dari semua yang kita lakukan, semua yang dipikirkan, semua yang dirasakan. ${ }^{5}$ Dengan karya penebusan-Nya yang dilakukan di atas kayu salib, diperbaharui relasinya yang dahulu rusak oleh karena ketidaktaatan manusia akan perintah Allah, telah terbuka jalan di mana manusia dapat secara langsung berjumpa dengan Tuhan. Oleh karena inisiatif dan cinta kasih Allah bagi umat-Nya, Dialah yang membuka tabir yang menjadi jarak antara keberdosaan manusia dengan kesucian Allah. Bahkan Allah sendiri yang menghancurkan tabir tersebut dengan curahan darah-Nya sehingga manusia yang dahulu tidak dapat menginjakkan kaki dalam hadirat Allah menjadi layak dan dapat mengalami secara pribadi kehadiran Allah oleh karena karya penebusan yang telah Yesus lakukan (Ibrani 10: 20-22). Melalui karya penebusan yang Allah lakukan agar manusia dapat secara sadar menerima dan mengalami hidup yang baru. Timbul pertanyaan apakah semua orang dapat mengerti karya penebusan yang Yesus lakukan?

Makhluk yang lemah dan tidak ada yang luput dari dosa. Dalam konteks inilah, maka Tuhan yang Maha Kuasa, memberikan fasilitas, yaitu pengampunan, kepada makhluk- makhlukNya yang berdosa. Hanya saja untuk mendapatkan pengampunan dari Tuhan, manusia yang berdosa itu haruslah bertobat, memohon ampun kepada Tuhan, dan berjanji untuk tidak mengulangi dosa dan kesalahan-kesalahannya di masa mendatang. ${ }^{6}$ Sehingga orang-orang dapat memperoleh bagian dalam penebusan dosa yang Tuhan Yesus telah lakukan di atas kayu salib.

Richard L. Pratt berpendapat bahwa orang-orang yang percaya dalam Kristus diperbarui secara terus-menerus menurut sifat mereka yang semula sebagai manusia yang diciptakan menurut gambar dan rupa Allah. ${ }^{7}$ seperti yang sudah penulis jelaskan pada bagian awal bab ini, bahwa masih banyak orang-orang yang berusaha mencari jalan keselamatan. Namun bersyukur menjadi orang-orang yang percaya, yang mungkin juga lahir dari keluarga kristen, pasti sudah mengenal Juruselamatnya yaitu Yesus Kristus dengan segala karya penebusan yng telah Ia selesaikan di atas kayu Salib. Namun pada kenyataannya tidak seperti yang dipikirkan. Karena masih banyak orang-orang kristen khususnya di kalangan kawula muda, yang akhirnya terjerat dengan cinta dunia, mengejar keinginan duniawi akhirnya lupa kepada siapa dia seharusnya menyerahkan seluruh hidupnya.

Seyogyanya, pengajaran penebusan dosa jelas di dalam kekristenan. Khususnya dalam setiap gereja Tuhan, pengajaran penebusan dosa seharusnya menjadi dasar di mana Kristus dapat masuk berperan sebagai penyelamatan yang menyatakan kemahakuasaan-Nya untuk menghapus dosa tersebut. Dalam karya ilmiah ini penulis fokus terhadap kalangan anak muda di gereja yang hidup dalam pergaulan yang luas, bagaimana mereka dapat bertumbuh dan mempertahankan iman mereka. Karena sebagai anak muda kristen seharusnya sudah memiliki pengertian yang kuat mengenai pengajaran penebusan dosa sehingga menolong mereka mengerti arti dari karya keselamatan yang Kristus sudah berikan di atas kayu salib. Ketika mengambil keputusan untuk menjadi pengikut Kristus, ada fondasi yang kuat di dalam membangun tubuh kristus sehingga kawula muda yang sebagai tulang punggung gereja terus menjadi generasi yang mencintai Tuhan menjujung tinggi iman serta tidak muda diombang ambingkan oleh pengajaran-

\footnotetext{
${ }^{5}$ Eka Darmaputera, Imamat Yang Rajani: Pemahaman Surat Ibrani Tentang Iman Dan Keimaman Yesus (Jakarta: BPK. Gunung Mulia, 2012), 131.

${ }^{6}$ Tarpin, "Pandangan Kristen Tentang Dosa: Asal Muasal dan Cara Menebusnya," Jurnal Ushuluddin 16, No. 2 (Juli 2010): 221, diakses 22 Februari 2019, http://ejournal.uinsuska.ac.id/index.php/ushuludin/article/view/677.

${ }^{7}$ Hengki Wijaya, "Pengenaan Manusia Baru Di Dalam Kristus: Natur, Proses, Dan Fakta Serta Implikasi Teologia dan Praktisnya," Jurnal Jaffray 14, No. 1 (April 2016): 110, diakses 22 Februari 2019, https://ojs.sttjaffray.ac.id/index.php/JJV71/article/view/194. Wijaya mengutip Richard L. Pratt, Menaklukan Segala Pikiran Kepada Kristus (Malang: Seminari Alkitab Asia Tenggara, 2003), 57, 58.
} 
pengajaran yang menyesatkan (Ef. 4:12-16). Apalagi sampai meninggalkan iman percaya kepada sang pemberi keselamatan itu.

Di kalangan Pemuda Kristen di Jemaat Imanuel Lambarese khususnya, sudah dilaksanakan program katekisasi bagi anak muda di mana di dalamnya dilakukan pengajaran tentang Alkitab khususnya karya yang Tuhan Yesus telah lakukan yaitu penebusan dan keselamatan yang cuma-cuma Tuhan Yesus berikan, hanya dengan percaya saja kita dapat menerima-Nya. Sehingga kaum muda yang telah lulus mengikuti program katekisasi telah siap mengikut Kristus serta di sahkan melalui peneguhan Sidi di gereja dan diberi sertifikat sebagai simbol dan tanda bahwa telah menjadi milik Kristus. Namun, pada kenyataan yang terjadi bahwa kawula muda kurang memahami bahkan tidak bertanggung jawab atas iman percayanya bahkan ada beberapa yang meninggalkan Tuhan yang telah memberi keselamatan. Yang menjadi pertanyaan apakah benar pemuda kristen khususnya di kalangan Gereja Kristen Sulawesi Tengah (GKST) di Jemaat Imanuel Lambarese telah mengenal karya penebusan yang telah Yesus lakukan dan sunggguh mengalami karya keselamatan yang Tuhan Yesus berikan dengan cumacuma secara pribadi.

Dengan melihat keadaan di kalangan Pemuda GKST Jemaat Imanuel Lambarese, serta berdasarkan uraian di atas, penulis tertarik melakukan penelitian dan menulis skripsi, PENGAJARAN PENEBUSAN DOSA TERHADAP KEYAKINAN KESELAMATAN DI KALANGAN PEMUDA GKST JEMAAT IMANUEL LAMBARESE.

\section{Pokok Masalah}

Sesuai dengan penjelasan latar belakang, yang menjadi pokok masalah yang diajukan pada penelitian ini adalah bagaimana Pengajaran Penebusan dosa terhadap keyakinan keselamatan di kalangan Pemuda GKST Jemaat Imanuel Lambarese.

\section{Tujuan Penelitian}

Merujuk pada pokok masalah di atas, maka tujuan penulisan yang hendak dipakai adalah untuk mengetahui bagaimana pengajaran penebusan dosa terhadap keyakinan keselamatan di kalangan Pemuda GKST Jemaat Imanuel Lambarese.

\section{Manfaat Penelitian}

Adapun manfaat penulisan skripsi antara lain:

Pertama, dengan penulisan skripsi ini kiranya dapat menjadi pedoman bagi penulis sebagai pengajar di lingkungan di mana penulis itu berada.Penelitian ini diharapkan dapat menjadi kontribusi pemikiran bagi semua Civitas Akademika STF Jaffray Makassar khususnya dalam pengembangan tentang pengajaran penebusan dosa terhadap keyakinan keselamatan. pemuda.

Kedua, penelitian ini diharapkan dapat menjadi masukkan bagi gereja dan kalangan

Ketiga, sebagai sarana untuk saran dan masukan bagi setiap orang tentang pengajaran penebusan dosa terhadap keyakinan keselamatan sehingga setiap orang mampu mempertahankan imannya.

Keempat, untuk memenuhi salah satu syarat akademik dalam menyelesaikan Stratum Satu (S-1), Program Studi Pendidikan Agama Kristen pada Sekolah Tinggi Filsafat Jaffray Makassar. 


\section{Metode Penelitian}

Dalam penulisan karya tulis ini metode yang digunakan adalah:

Pertama, dengan melakukan penelitian kualitatif (Wawancara) di kalangan Pemuda GKST Jemaat Imanuel Lambarese.

Kedua, penulis juga menggunakan teknik pengumpulan datamelalui metode kualitatif atau Library Research di mana penulis menggunakan Alkitab sebagai sumber primer dan menggunakan buku-buku tambahan yang berkaitan dengan pokok pembahasan di atas, sebagai sumber sekunder dalam penelitian dan pengumpulan data dalam mengungkapkan kebenaran.

Ketiga, observasi langsung, di mana penulis menjadi pengamat meninjau secara langsung keadaan dan sikap dari anak muda di kalangan GKST Jemaat Imanuel Lambarese.

\section{Batasan Penelitian}

Ruang lingkup penulisan skripsi ini terbatas pada pengajaran penebusan dosa terhadap keyakinan keselamatan di kalangan Pemuda GKST Jemaat Imanuel Lambarese.Selain itu, penulis juga mengambil ayat-ayat dari kitab-kitab lain sebagai pendukung dan bahan perbandingan saja.

\section{Sistematika Penulisan}

Sistematika penulisan karya ilmiah ini adalah sebagai berikut:

Bab I, merupakan pendahuluan yang meliputi: latar belakang masalah, pokok masalah, tujuan penelitian, manfaat penelitian, batasan penelitian, metode penelitian, dan sistematika penulisan.

Bab II, kajian Teori Pengajaran Penebusan Dosa dan Keyakinan Keselamatan.

Bab III, metode penelitian gambaran umum lokasi penelitian, populasi dan sampel, teknik analisa data. analisa data.

Bab IV, analisa hasil penelitian dan pembahasan. Subjek penelitian dan kesimpulan

$\mathrm{Bab} \mathrm{V}$, merupakan penutup yang berisi kesimpulan dan saran.

\section{Kesimpulan}

Berdasarkan analisa hasil penelitian dan pembahasan data yang telah dilakukan oleh penulis dapat ditarik beberapa kesimpulan sebagai berikut:

Pertama, dari analisis deskripsi bahwa pengajaran penebusan dosa sangat penting di kalangan pemuda GKST Jemaat Imanuel Lambarese.Karena, pengajaran penebusan dosa masih minim dalam pemahamanpemuda-pemudi yang melatar belakangi keberdosaan manusia di dalam dunia ini.

Kedua, dengan adanya pengajaran penebusan dosa, mendukung pemuda-pemudi untuk memahami karya penebusan yang dilakukan oleh Yesus. Pengajaran penebusan dosa telah diberikan olehgereja sebagai materi pembinaan iman kaum muda (katekisasi) untuk mengikuti peneguhan sidi gereja, yang di dalamnya ada pengakuan dan komitmen untuk menjadi pengikut Kristus yang setia dan berpartisipasi atas pengembangan organisasi gereja. 
Ketiga, pemuda harus memiliki dasar yang kuat akan keyakinan keselamatan yang telah dianugerahkan oleh Yesus di dalam penebusan-Nya. keyakinan keselamatan yang benar dipengaruhi oleh pengajaran yang diterima. Oleh karena itu pengajaran penebusan dosa sangat menentukan keyakinan keselamatan pemuda. Maka, gereja perlu meningkatkan isi maupun metode atau cara pengajaran.

\section{Saran-saran}

Berdasarkan hasil penelitian maka beberapa saran berikut diharapkan penulis dapat bermanfaat untuk dapat dilaksanakan sebagai berikut:

Pertama, gereja perlu meningkatkan isi maupun metode atau cara dalam pengajaran penebusan dosa. Serta, memberikan waktu yang maksimaluntuk pengajaran penebusan dosa. Karena, pengajaran ini penting untuk mendukung serta memberikan pemahaman bagi pemudaakan keyakinan keselamatan yang diperoleh.

Kedua, kepada pembina pemuda (penatua) GKST Jemaat Imanuel Lambarese, harus memperhatikan pengajaran penebusan dosa,sehingga pembina dapat membimbing pemudapemudi untuk menghasilkan pemuda-pemudi yang memiliki keyakinan keselamatan yang teguh di dalam Tuhan.

Ketiga, kepada pemuda-pemudi di GKST Jemaat Imanuel Lambarese, ketika diberikan pengajaran penebusan dosa, baik di gerejadalam pembinaan iman (katekisasi) maupun melalui bimbingan untuk dapat mengikuti serta memperhatikan pengajaran tersebut. Agar, pemuda memiliki pemahaman yang luas dan memperkuat keyakinan keselamatan yang telah dianugerahkan oleh Kristus.

\section{Kepustakaan}

Alkitab. Jakarta: Lembaga Alkitab Indonesia, 2015.

Berkhof, Louis. Teologi Sistematika: Doktrin Manusia. Jakarta: Lembaga Reformed Injil, 1994. . Teologi Sistematika: Doktrin Keselamatan. Jakarta: Lembaga Reformed Injili Indonesia, 1997.

Bridges, Jerry. Respectable Sins: Dosa-dosa yang Dianggap Pantas; Membereskan Dosa-dosa yang Kita Toleransi. Bandung: Pionir Jaya, 2014.

Brill, J. Wesley. Dasar yang Teguh. Bandung: Kalam Hidup, 2011.

Browning, W. R. F. Kamus Alkitab, A Dictionary of the Bible: Panduan Dasar ke dalam Kitabkitab, Tema, Tempat, Tokoh, dan Istilah Alkitab. Jakarta: BPK Gunung Mulia, 2016.

Darmaputera, Eka. Imamat Yang Rajani: Pemahaman Surat Ibrani Tentang Iman Dan Keimaman Yesus. Jakarta: Bpk. Gunung Mulia, 2012.

Daun, Paulus. Keselamatan (Soteriologi) Dalam Kitab Roma. Manado: Yayasan Daun Family, 1998.

Erickson, Millard J. Teologi Kristen. Malang: Gandum Mas, 2004.

Ferguson, Sinclair B. Kehidupan Kristen: Sebuah Pengantar Doktrinal. Surabaya: Momentum, 2007.

Fransisca, Delvy dan Yunus D. A. Laukapitang. "Kepemimpinan Yosia Berdasarkan Kitab 2 Tawarikh 34:1-7 dan Implikasinya bagi Pelayanan Pemuda di Gereja." Jurnal Ilmu 
Teologi dan Pendidikan Agama Kristen 1, no. 2 (Desember 2020): 103-122. http://dx.doi.org/10.25278/jitpk.v1i2.508.

Graham, Billy. Damai dengan Allah. Jakarta: BPK Gunung Mulia, 1974.

Hadiwijono, Harun. Inilah Sahadatku. Jakarta: BPK GunungMulia,2017.

Henry, Matthew. Tafsiran Matthew Henry: Surat Ibrani, Yakobus, 1 \& 2 Petr. $1-3$ Yoh. Yudas, Kitab Wahyu. Surabaya: Momentum, 2016.

Douglas, J. D. Ensiklopedia Alkitab Masa Kini Jilid I. Jakarta: Yayasan Komunikasi Bina Kasih/OMF, 1995.

Hoekema, Anthony A. Manusia: Ciptaan Menurut Gambar Allah: Created in God's Image. Surabaya: Momentum, 2008.

Hunter, A. M. Yesus Tuhan dan Juruselamat. Jakarta: BPK Gunung Mulia, 1990.

Kamus Besar Bahasa Indonesia. Jakarta: Balai Pustaka, 2001.

Kee, Howard Clark, (ed). dkk. Alkitab Edisi Studi. Jakarta: Lembaga Alkitab Indonesia, 2012.

M, John, John Blase. Pandangan Dunia: Bagaimana Orang-orang memandang Tuhan. Yogyakarta: Yayasan Gloria, 2011.

Murray, John. Penggenapan dan Penerapan Penebusan.Surabaya: Momentum, 2010.

Owen, John. Kematian yang Menghidupkan:The Death oh Death in the Death of Christ. Surabaya: Momentum, 2011.

Palmer, Edwin H.Lima Pokok Calvinisme. Jakarta: Lembaga Reformed Injil Indonesia. 1996.

Park, Abraham. Imam Besar Kekal yang Dijanjikan dengan Sumpah: Silsilah Imam Besar Dilihat dari Sudut Pandang Sejarah Penbusan. Depok: Yayasan Damai Sejahtera Utama, 2017.

Park, Abraham. Pelita Perjanjian yang tak Terpadamkan: Silsilah Yesus Kristus (I), AbrahamDaud.Jakarta: Grasindo, 2012.

Park, Abraham. Pemeliharaan yang Misterius dan Ajaib: Silsilah Yesus Kristus (II), Sejarah Raja-raja. Jakarta: Grasindo, 2013.

Park, Abraham. Pertemuan yang Terlupakan: Dilihat dari Sudut Pandang Penyelenggaraan Sejarah Penebusan.Jakarta: Grasindo, 2011.

Park, Abraham. Silsilah di Kitab Kejadian: Dilihat dari Sudut Pandang Penyelenggaraan Sejarah Penebusan. Jakarta: Grasindi, 2010.

Pink, Arthur W. The Sovereignty of God: Kedaulatan Allah. Surabaya: Momentum, 2005.

Rajo, Gabriel Yobert. "Dosa Yerusalem dalam Yehezkiel 22:1-31: Kajian Biblika dan Implikasi Praktis." Jurnal Ilmu Teologi dan Pendidikan Agama Kristen 1, no. 2 (Desember 2020): 144-162. https://ojs.sttjaffray.ac.id/jitpk/article/view/518.

Roberts, Vaughan. Gambar Besar dari Allah: Menelusuri Alur Cerita Alkitab. Jakarta: Literatur Perkantas, 2014.

Ryken, Leland. James C. Wilhoit. Tremper Longman III. Kamus Gambaran Alkitab. Surabaya: Momentum, 2011.

Ryrie, Charles C.Teologi Dasar: Pandangan Populer untuk memahami kebenaran Alkitab. Yogyakarta: Yayasan ANDI, 1992.

Sadono, Sentot. Doktrin Baptis: Diantara Pandangan Teologi Kristen. Semarang: Program Pascasarjana Sekolah Tinggi Theologia Baptis Indonesia, 2011.

Siburian, Togardo. Sola Scriptura: dan Pergumulannya Masa Kini. Bandung: STT Bandung, 2005

Sihombing, Lotnatigor. Teologi Sistematika. Jakarta: STT Amanat Agung, 2016.

Simpson, A. B.Empat Injil Berganda Cetakan. Bandung: BPK Gunung Mulia, 2016. 
Soedarmo. Ikhtisar Dogmatika. Jakarta: BPK Gunung Mulia, 1985.

Sproul, R.C.Kebenaran-kebenaran Dasar Iman Kristen.Malang: Seminar Alkitab Asia Tenggara, 2002.

Kaum Pilihan Allah.Malang: Seminar Alkitab Asia Tenggara, 1996.

Stamps, Donald C. (ed.). Alkitab Penuntun Hidup Berkelimpahan. Malang: Gandum Mas, 2010.

Sudhiarsa, Raymundus I Made. "Doing Theology And Our Theological Education: An Indonesian Perspective." International Journal of Indonesian Philosophy \& Theology 1, no. 2 (Desember 2020): 105-115. https://aafki-afti.org/IJIPTh/article/view/10.

Tarpin. "Pandangan Kristen Tentang Dosa: Asal Muasal dan Cara Menebusnya," Jurnal Ushuluddin 16 No. 2, (Juli 2010): 1-13. Diakses 22 Februari 2019 http://ejournal.uinsuska.ac.id/index.php/ushuludin/article/view/677.

Thiessen, Henry C. Teologi Sistemaika. Malang: Gandum Mas, 1992.

Vangemeren, Willem A. Progres Penebusan: Kisah Keselamatan dari Penciptaan sampai Yerusalem Baru. Surabaya: Momentum, 2016.

Wijaya, Hengki. "Pengenaan Manusia Baru Di Dalam Kristus: Natur, Proses, Dan Fakta Serta Implikasi Teologia dan Praktisnya," Jurnal Jaffray 14, No. 1, (April 2016): 109-130. Diakses 22 Februari 2019 https://ojs.sttjaffray.ac.id/ index.php/JJV71/article/view/194.

\section{Wawancara}

Agnes. Wawancara Oleh Penulis. Lambarese, 17 Juli 2019.

Azen, Ivan. Wawancara Oleh Penulis. Lambarese, 18 Juli 2019.

Efraim, Raul. Wawancara Oleh Penulis. Lambarese, 19 Juli 2019.

Franz. Wawancara Oleh Penulis. Lambarese, 18 Juli 2019.

Ismail, Rifka Ismail. Wawancara Oleh Penulis. Lambarese, 18 Juli 2019.

Oskar. Wawancara Oleh Penulis. Lambarese, 18 Juli 2019.

Raganti, Vion. Wawancara Oleh Penulis. Lambarese, 17 Juli 2019.

Raya, Des Mulya. Wawancara Oleh Penulis. Lambarese, 15 Juli 2019.

Rit. Wawancara Oleh Penulis. Lambarese, 17 Juli 2019.

Sinta. Wawancara Oleh Penulis. Lambarese, 19 Juli 2019.

Tiansi. Wawancara Oleh Penulis. Lambarese, 19 Juli 2019.

Vein, Elma. Wawancara Oleh Penulis. Lambarese, 18 Juli 2019.

Yefta. Wawancara Oleh Penulis. Lambarese, 19 Juli 2019.

Yesmin. Wawancara Oleh Penulis. Lambarese, 18 Juli 2019. 